BMJ Open Sport \& Exercise Medicine

\title{
Interval exercise increases angiogenic cell function in postmenopausal women
}

\author{
Emma Harris, ${ }^{1}$ Mark Rakobowchuk, ${ }^{2}$ Karen M Birch ${ }^{3}$
}

To cite: Harris $\mathrm{E}$,

Rakobowchuk M, Birch KM. Interval exercise increases angiogenic cell function in postmenopausal women. BMJ Open Sport Exerc Med 2017;3:e000248.

doi:10.1136/bmjsem-2017000248

Accepted 20 June 2017

\section{CrossMark}

\footnotetext{
${ }^{1}$ School of Human and Health Sciences,University of Huddersfield, Huddersfield, UK

${ }^{2}$ Department of Biological Sciences, Faculty of Science, Thompson Rivers University, Kamloops, British Columbia, Canada

${ }^{3}$ Multidisciplinary

Cardiovascular Research Centre, Faculty of Biological Sciences, University of Leeds, Leeds, UK

Correspondence to Dr Karen M Birch, School of Biomedical Sciences,Faculty of Biological Sciences, University of Leeds,Leeds, LS2 9JT; k.m.birch@leeds. ac.uk
}

\section{ABSTRACT}

Introduction Exercise can help to negate the increased cardiovascular disease risk observed in women after the menopausal transition. This study sought to determine whether interval or continuous exercise has differential effects on endothelial function and circulating angiogenic cell (CAC) number and function in postmenopausal women.

Methods Fifteen healthy postmenopausal women completed a 30 min acute moderate-intensity continuous (CON) and interval exercise (MOD-INT) session on a cycle ergometer on separate days. Nine participants completed a further single 30 min acute heavy-intensity interval (HEAVY-INT) exercise session. Brachial artery flow-mediated dilation (FMD) was assessed pre-exercise and 15 min post-exercise session. CAC number and colony-forming capacity in vitro were assessed post exercise and compared with resting levels.

Results FMD and CAC number did not change post exercise regardless of exercise type $(p>0.05)$. However, the number (mean $\pm \mathrm{SD}$ ) of colony-forming units (CFUs) increased from visit 1 (12 $\pm 10 \mathrm{CFUs} /$ well) to post MODINT (32 $\pm 30 \mathrm{CFUs} /$ well) and post HEAVY-INT (38 \pm 23 CFUs/well) but not post CON ( $13 \pm 14$ CFUs/ well).

Conclusion A single session of interval exercise is more effective than a continuous exercise session for increasing the intercellular communication of CACs, regardless of exercise intensity. The enhanced ability of CACs to form colonies may reflect an increased number and/or function of angiogenic T-cells. The repeated exertions to higher work rates during interval exercise may explain this response. Repeated exercise sessions might be required to improve FMD in postmenopausal women.

\section{INTRODUCTION}

The risk of cardiovascular disease (CVD) in women increases during perimenopause and postmenopause primarily due to the loss of oestrogen. This hormonal change, in addition to increasing age, reduces endothelial function ${ }^{1}$ and the number and function of circulating angiogenic cells (CACs; ${ }^{15}$ ). CACs migrate and aggregate to areas of vascular damage and aid in endothelial repair through the secretion of proangiogenic cytokines and growth factors. ${ }^{2}$ Low levels of CACs in circulation

\section{What are the new findings?}

- An acute bout of interval exercise increases the ability of circulating angiogenic cells to form colonies, which may increase the capacity for vascular repair in postmenopausal women.

- The government-recommended guidelines of 30 min of moderate-intensity continuous exercise did not acutely impact endothelial function or factors associated with repair in postmenopausal women.

How might it impact on clinical practice in the near future?

The findings provide support for individualised exercise prescription for postmenopausal women.

- Healthcare professionals may advise postmenopausal women to exercise in short bursts of activity followed by active rest periods for vascular benefits.

and reduced function following culture (ie, impaired colony-forming capacity) are associated with an increased risk of developing CVD. ${ }^{3}$ Fewer numbers of colony-forming units (CFUs) are associated with poorer brachial artery endothelial function and increased severity of coronary artery disease. $^{4} \quad{ }^{5}$ Decreased oestrogen levels significantly impact the capacity for endothelial repair. ${ }^{6}$ Thus, the reduction in endothelial function and inability of CACs to aid in vascular repair following the menopausal transition indicates an imbalance in vascular homeostasis and plays a part in CVD risk.

Lifestyle interventions such as exercise are recommended for postmenopausal women as a preventative strategy for CVD. ${ }^{7}$ Aerobic exercise training studies in postmenopausal women have demonstrated improved endothelial function ${ }^{8}$ and reduced oxidative stress. ${ }^{9}$ However, the effect of exercise on CAC number and function in 
postmenopausal women has not been studied. Recent evidence suggests that interval exercise is more or equally effective as UK government guidelines for moderate-intensity continuous exercise in improving cardiorespiratory fitness, endothelial function and arterial stiffness. ${ }^{10} 11$ We have suggested that interval exercise performed at a heavy intensity may induce an increase in CAC number compared with moderateintensity exercise, likely due to greater metabolic stress. $^{2} 12$ However, a comparison between the effects of interval and continuous exercise on endothelial function, CAC number and function of these cells has not been examined in postmenopausal women.

The aims of this study were to (1) compare the acute effects of moderate-intensity continuous and interval exercise, on endothelial function and CAC number/ function in postmenopausal women, and (2) compare these effects with an interval exercise session performed in the heavy-intensity domain. Endothelial function measured by brachial artery flow-mediated dilation (FMD) was the primary outcome. Secondary outcomes were brachial artery diameter, shear rate and reactive hyperaemic variables and CAC number and function. We did not include a session of heavy-intensity continuous exercise as reports suggest that postmenopausal women dislike exercise of this nature. ${ }^{13}$ Investigating the acute effects of exercise on vascular health allows identification of (1) exercise that has an immediate impact and (2) the type and intensity of exercise that may yield the greatest improvements if undertaken chronically. We hypothesised that interval exercise would be tolerable and would improve markers of vascular health and repair to a greater extent than continuous exercise due to the brief excursions to higher work rates.

\section{METHODS}

\section{Participants}

Fifteen healthy postmenopausal women (age: $63 \pm 4$ years) volunteered for the study and provided written informed consent. Postmenopausal status was defined as absence of a menstrual cycle for $>2$ years and confirmed through follicle stimulating hormone $>30 \mathrm{iU} / \mathrm{L}$. Exclusion criteria included smoking, known cardiovascular, pulmonary and metabolic disease, musculoskeletal impairments, cancer, contradictions to exercise, medication use (eg, hormone replacement therapy) and if participants had given blood in the previous three months. Participants were not currently exercising more than twice per week. Ethical approval was provided by the University of Leeds Faculty of Biological Sciences Ethics Committee and all procedures conformed to the Declaration of Helsinki.

\section{Experimental protocol}

For the assessment of endothelial function and calculation of work rate for the exercise bouts, participants attended the laboratory on two occasions (separated by 1 week). Participants were instructed to refrain from exercise participation and consuming alcohol and caffeine for 12 hours prior to each visit. At the first visit, a fasted blood sample $(\sim 50 \mathrm{~mL})$ for the assessment of CVD risk blood markers and CAC number and function was completed. At the second visit, a cardiorespiratory fitness test was completed to determine peak aerobic capacity $\left(\dot{V} O_{2 p e a k}\right)$ and lactate threshold. On three further occasions, each separated by $\geq 1$ week (to allow exercise-induced changes in CACs to return to baseline levels), participants completed $30 \mathrm{~min}$ of either moderate-intensity continuous (CON), moderate-intensity interval (MOD-INT) or heavyintensity interval (HEAVY-INT) exercise bouts. Only nine participants completed the heavy-intensity bout. To assess the acute effects of each exercise bout on endothelial function, assessments were completed before and $15 \mathrm{~min}$ after exercise. For CAC number and function, blood samples were acquired $30 \mathrm{~min}$ post exercise and results compared with that of visit 1 .

\section{Variables assessed before and after exercise sessions Cardiorespiratory fitness}

A seated ramp-incremental exercise test $(10 \mathrm{~W} / \mathrm{min})$ was performed for the assessment of $\dot{V} O_{2 p e a k}$ and the lactate threshold, and for calculation of the work rates achieved at these points. These values were used to establish work rates for the subsequent exercise sessions. Participants were seated on an electronically braked cycle ergometer (Excalibur Sport V.2.0; Lode BV, Groningen, The Netherlands) and a mouthpiece and nose clip were fitted for breath by breath analysis of pulmonary gas exchange. The protocol has been described in detail previously. ${ }^{12}$ Heart rate, blood pressure and rating of perceived exertion (Borg's scale of rating of perceived exertion) were measured every 2 min during the test using a 12-lead ECG, sphygmomanometer and a visual scale of exertion (6-20), respectively. The work rate at the end of the rampincremental test was calculated as test duration $\times$ ramp rate $(10)+20 \mathrm{~W}$. Breath-by-breath data were exported and analysed using OriginPro software (OriginPro 8, OriginLab, Northampton, Massachusetts, USA). Breaths were eliminated if $\dot{V} O_{2 p e a k}$ values fell outside 4 SD from the local mean. As previously described, ${ }^{24}$ a 12-breath moving average was calculated and the highest value was defined as $\dot{V} O_{2 p e a k}$. The estimated lactate threshold was determined using the V-slope method $^{25}$ and confirmed by a rise in end-tidal $\mathrm{O}_{2}$ and plateau in end-tidal $\mathrm{CO}_{2}$. 
Endothelial function

Endothelial function was assessed in the morning in a temperature-controlled laboratory $\left(20-24^{\circ} \mathrm{C}\right)$ after 20 min supine rest. The protocols for our lab have been described in detail elsewhere. ${ }^{2}{ }^{12}$ Briefly, endothelial function was assessed by brachial artery FMD using ultrasound imaging following a 5 min period of forearm occlusion. Images were recorded at end-diastole using vascular imaging software (Vascular Imager, Medical Imaging Applications, Coralville, Iowa, USA) and analysed using semiautomated edge-detection software (Brachial Tools V.5, Medical Imaging Applications) to determine brachial artery diameter. Peak reactive hyperaemia, peak shear rate, area under the shear rate curve from cuff release to peak dilation $\left(\mathrm{AUC}_{\text {peak }}\right)$ and to $60 \mathrm{~s}\left(\mathrm{AUC}_{60}\right)$ and $90 \mathrm{~s}\left(\mathrm{AUC}_{90}\right)$ post cuff release, and their corresponding velocity time integrals (VTIs) were also calculated. FMD was not normalised to shear rate/AUC as not all assumptions for the use of ratios were met. ${ }^{26}$ During recording of blood velocity, the insonation angle for each participant before and after exercise and between different exercise visits was within $2^{\circ}$. Day-to-day coefficient of variation for FMD in our lab is $15 \% .^{2}$

\section{Blood markers and CAC number and function}

Visit 1 blood samples were analysed by local hospital pathology services for serum follicle stimulating hormone levels, lipoproteins, insulin, glucose and HbAlc. CACs were enumerated from $22 \mathrm{~mL}$ of blood via flow cytometry using a commercially available kit (Miltenyi Biotec) as previously described. ${ }^{2}$ CACs were defined as $\mathrm{CD} 34^{+}$, double positive $\left(\mathrm{CD} 34^{+} \mathrm{KDR}^{+}\right)$or triple positive $\left(\mathrm{CD} 34^{+} \mathrm{KDR}^{+} \mathrm{CD} 133^{+}\right)$. To assess the in vitro function of CACs, a CFU assay was performed, according to the manufacturer's instructions. Briefly, peripheral blood mononuclear cells were separated by Ficoll density-gradient centrifugation of whole blood (Ficoll Paque PLUS, GE Healthcare, Buckinghamshire, UK), and $5 \times 10^{6}$ cells were suspended in $2 \mathrm{~mL}$ of EndoCult growth medium (StemCell Technologies, Vancouver, Canada) and cultured in one well of a fibronectin-coated six-well plate for 48 hours at $37^{\circ} \mathrm{C}$ in $5 \%$ $\mathrm{CO}_{2}$. After 48 hours, the non-adherent cells were collected from the well and seeded in duplicate on a 24-well fibronectin-coated plate at a density of $1 \times 10^{6}$ cells/well. Following three further days of culture, the non-adherent cells were removed and the number of CFUs per well counted and an average calculated. CFUs were defined as clusters of $>100$ round cells with spindle-shaped cells surrounding the core.

\section{Exercise session protocols}

Participants completed $30 \mathrm{~min}$ CON, MOD-INT and HEAVY-INT exercise bouts on a cycle ergometer (Excalibur Sport V.2.0) on separate days. Duration of $30 \mathrm{~min}$ was chosen as it reflects the current UK
Department of Health guidelines of $30 \mathrm{~min}$ of moderate-intensity exercise, 5 days/week (ref. ${ }^{27}$; p. 34 ). CON exercise involved cycling at $80 \%$ of the work rate achieved at the lactate threshold (moderate-intensity domain as $\dot{V} O_{2 p e a k}$ remained below the lactate threshold ${ }^{28}$ ). The interval exercise bouts were based on work by Turner et al. ${ }^{29}$ Thus, our participants cycled at $90 \%$ of the work rate achieved at $\dot{V} O_{2 p e a k}$ for duty cycles of 10:20 s for MOD-INT and 30:60 s for HEAVY-INT exercise. Active recovery was conducted at $10 \mathrm{~W}$ and confirmation of intensity domain was confirmed by stabilisation of oxygen uptake above or below the lactate threshold accordingly. By design the MOD-INT and HEAVY-INT exercise bouts were matched for average work rate and work completed.

\section{Statistical analysis}

All analyses was completed using SPSS V.22. Data were assessed for normal distribution via KolmogorovSmirnov. A non-parametric Friedman's analysis of variance (ANOVA) was conducted on CAC number only as data were not normally distributed and could not be transformed. The remaining data were examined by a mixed-design ANOVA with time (pre vs post exercise) as the within-subject factor and exercise bout $(\mathrm{CON}$, MOD-INT and HEAVY-INT) as the between-subject factor. Pearson's correlations were performed between $\dot{V} O_{2 p e a k}$, blood pressure, full lipid profile and the change in CFUs post exercise. Using previously reported acute increases of $4.6 \%$ in FMD following $45 \mathrm{~min}$ of treadmill exercise in postmenopausal women, ${ }^{17}$ and SD of $3 \%$ calculated from our lab, ${ }^{12}$ a minimum of nine participants in total were required to obtain $80 \%$ power $(\alpha=0.05)$ in a crossover study. Data are presented as mean $\pm \mathrm{SD}$ and percentage change with accompanying $95 \%$ CI.

\section{RESULTS}

\section{Participant and exercise session characteristics}

Participant characteristics are displayed in table 1 . Total cholesterol and low-density lipoprotein levels were higher than the desirable healthy range $(>5.2$ and $>3.4 \mathrm{mmol} / \mathrm{L}$, respectively) in nine and seven participants, respectively. By design, work completed $(54 \pm 3 \mathrm{~kJ})$ during MOD-INT and HEAVY-INT exercise sessions was equal. The average work rate of the peaks during MOD-INT and HEAVY-INT $(70 \pm 5 \mathrm{~W})$ were significantly higher than the average work rate of CON exercise $(35 \pm 6 \mathrm{~W})$.

\section{Brachial artery endothelial function}

Brachial artery endothelial function was unaltered by acute CON, MOD-INT and HEAVY-INT exercise $(p>0.05$, table 2). There were no significant post-exercise changes in brachial artery resting diameter $(p=0.72)$ or the associated shear rate and reactive 
Table 1 Participant characteristics of postmenopausal women at visit 1

\begin{tabular}{lll}
\hline & $\mathbf{n}$ & Mean $( \pm$ SD) \\
\hline Age (years) & 15 & $63 \pm 4$ \\
\hline BMI (kg/m) & 15 & $25 \pm 3$ \\
\hline Brachial artery SBP $(\mathrm{mm} \mathrm{Hg})$ & 15 & $137 \pm 15$ \\
\hline Brachial artery DBP $(\mathrm{mm} \mathrm{Hg})$ & 15 & $84 \pm 5$ \\
\hline Brachial artery MAP $(\mathrm{mm} \mathrm{Hg})$ & 15 & $102 \pm 8$ \\
\hline Absolute $\dot{V} O_{2 p e a k}(\mathrm{~L} / \mathrm{min})$ & 15 & $1.40 \pm 0.29$ \\
\hline Relative $\dot{V} O_{2 p e a k}(\mathrm{~mL} / \mathrm{kg} / \mathrm{min})$ & 15 & $21.6 \pm 5.4$ \\
\hline Plasma glucose $(\mathrm{mmol} / \mathrm{L})$ & 13 & $4.8 \pm 0.5$ \\
\hline HbA1c $(\mathrm{mmol} / \mathrm{mol} / \mathrm{HB})$ & 14 & $39 \pm 2$ \\
\hline Total cholesterol $(\mathrm{mmol} / \mathrm{L})$ & 14 & $5.9 \pm 1.0$ \\
\hline HDL $(\mathrm{mmol} / \mathrm{L})$ & 14 & $1.9 \pm 0.5$ \\
\hline LDL $(\mathrm{mmol} / \mathrm{L})$ & 14 & $3.5 \pm 0.8$ \\
\hline Cholesterol:HDL ratio & 14 & $3.1 \pm 0.7$ \\
\hline Triglycerides $(\mathrm{mmol} / \mathrm{L})$ & 14 & $1.0 \pm 0.4$ \\
\hline FSH (iU/L) & 13 & $69.9 \pm 31.0$ \\
\hline Insulin (mU/L) & 14 & $6.5 \pm 3.1$ \\
\hline
\end{tabular}

BMI, body mass index; DBP, diastolic blood pressure; FSH, follicle-stimulating hormone; HbA1c, haemoglobin A1c; HDL, high-density lipoprotein; LDL, low-density lipoprotein; MAP, mean arterial pressure; SBP, systolic blood pressure.

Table 2 Brachial artery endothelial function (mean \pm SD) pre and post an acute 30 min bout of moderate-intensity continuous (CON, $n=15)$, moderate-intensity interval (MOD-INT, $n=14$ ) and heavy-intensity interval (HEAVY-INT) exercise $(n=9)$

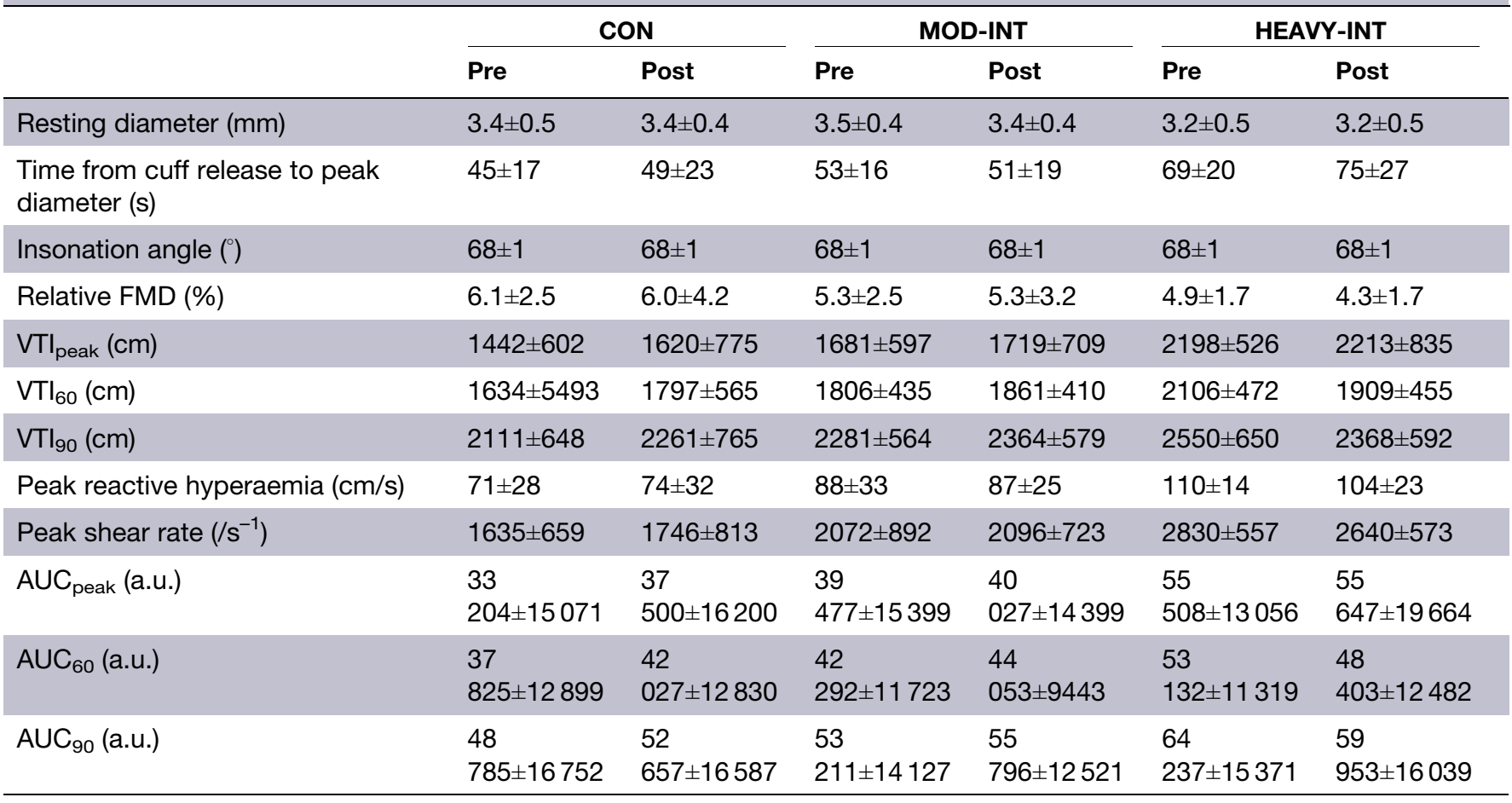

No significant effects of exercise or group by time interactions were revealed ( $p>0.05)$.

AUC, shear rate area under the curve; FMD, flow-mediated dilation; VTI, velocity-time integral. 
Table 3 Circulating angiogenic cell number ( $m e a n \pm S D$ ) at visit 1 and post an acute $30 \mathrm{~min}$ bout of moderate-intensity continuous (CON) and interval (MOD-INT) exercise and heavy-intensity interval (HEAVY-INT) exercise

\begin{tabular}{lllll}
\hline & Visit 1 & CON & MOD-INT & HEAVY-INT \\
\hline $\mathrm{CD} 4^{+}$cells $/ \mathrm{mL}$ blood & $2.7 \pm 1.3 \times 10^{5}$ & $2.2 \pm 1.2 \times 10^{5}$ & $2.6 \pm 1.1 \times 10^{5}$ & $2.3 \pm 0.9 \times 10^{5}$ \\
$\mathrm{CD} 34^{+} \mathrm{KDR}^{+}$cells $/ \mathrm{mL}$ blood & $251 \pm 176$ & $108 \pm 119$ & $244 \pm 188$ & $144 \pm 201$ \\
$\mathrm{CD}^{+} 4^{+} \mathrm{KDR}^{+} \mathrm{CD} 133^{+}$cells $/ \mathrm{mL}$ blood & $68 \pm 102$ & $11 \pm 13$ & $40 \pm 85$ & $14 \pm 26$ \\
\hline
\end{tabular}

No significant effects of exercise or group by time interactions were revealed $(p>0.05)$.

hyperaemic variables $(\mathrm{p}>0.05)$. Additionally, there were no time by exercise interactions $(\mathrm{p}>0.05)$.

\section{CAC number}

Neither CON nor MOD-INT exercise altered concentrations of $\mathrm{CD}^{+} 4^{+}(\mathrm{p}=0.28), \mathrm{CD} 34^{+} \mathrm{KDR}^{+}(\mathrm{p}=0.57)$ or $\mathrm{CD}^{+} 4^{+} \mathrm{KDR}^{+} \mathrm{CD} 133^{+}$cells $(\mathrm{p}=0.74)$. In addition, there was no change in any CAC population following HEAVY-INT ( $>>0.05$, table 3$)$. No time by exercise bout interactions were observed $(\mathrm{p}>0.05)$.

\section{CFU numbers}

A significant time effect $(p=0.0001)$ and time by exercise bout interaction $(p=0.017)$ for CFU number was revealed. The analysis of the means and $95 \% \mathrm{CI}$ for pre exercise and post exercise (figure 1) illustrates that CFU number increased following MOD-INT (pre: 12.2 CFUs, 95\% CI 6.4 to 17.9; post: 32 CFUs, 95\% CI 19.4 to 44.7 ) and HEAVY-INT (pre: 11.2 CFUs, 95\% CI 4.1 to 18.3 ; post: 37.8 CFUs, 95\% CI 22 to 53.6) but remained unchanged following CON (pre: 12.2 CFUs, 95\% CI 6.4 to 17.9 ; post: $12.8 \mathrm{CFUs}$, $95 \% \mathrm{CI} 0.2$ to 25.5). There was no correlation between the change in CFUs and pre-exercise $\dot{V} O_{2 p e a k}$, blood pressure or cholesterol levels $(\mathrm{p}>0.05)$.

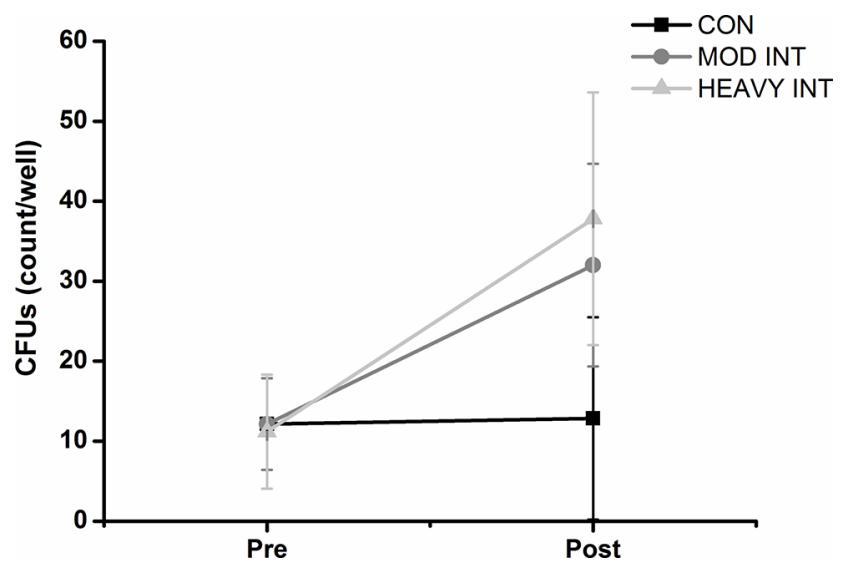

Figure 1 The number (mean with $95 \% \mathrm{Cl}$ ) of colonyforming units (CFUs) at visit 1 and following a $30 \mathrm{~min}$ moderate-intensity continuous (CON), moderate-intensity interval (MOD-INT) and heavy-intensity interval (HEAVY-INT) exercise bout. CFUs increased following the MOD-INT $(n=14)$ and the HEAVY-INT $(n=9)$ exercise bouts, but not following CON $(n=14)$.

\section{DISCUSSION}

The present study was the first to compare the acute effects of continuous and interval exercise on endothelial function and CAC number and function in postmenopausal women. The population of postmenopausal women studied were healthy but presented risk factors for CVD. The main findings were that moderate-intensity continuous exercise had no immediate effect on endothelial function or CAC concentrations or function. Conversely, MOD-INT and HEAVY-INT exercise acutely increased the ability of cultured CACs to form colonies in vitro. Presentation of CVD risk factors did not influence this effect.

\section{Continuous and interval exercise did not acutely effect endothelial function}

Brachial artery endothelial function did not change following any of the exercise bouts. In response to lower-limb exercise, measurement of upper limb vascular function is used to reflect systemic endothelial function. Our findings suggest that for increases in systemic endothelial function in postmenopausal women to occur, a greater stimulus or repeated acute exercise bouts are required. Indeed, an absolute increase of $\sim 5 \%$ in brachial artery FMD was observed by Harvey et al. following $45 \mathrm{~min}$ of continuous treadmill exercise at $60 \% \dot{V} O_{2 \max }$, in postmenopausal women with similar FMD values as in the present study $(\sim 5 \%$; $\left.{ }^{17}\right)$. Greater endothelial function following exercise is mediated by shear stress-induced increases in nitric oxide bioavailability which induces vasodilation. ${ }^{21}$ The exercise duration was greater in Harvey's study and a different definition of intensity adopted compared with the present study. It is likely that a greater volume/ magnitude of shear was thus induced.

HEAVY-INT exercise may well have been expected to induce higher levels of shear stress; however, compared with the women studied by Harvey et al., women in the present study were older $(64 \pm 4$ years vs $54 \pm 2$ years) and had greater blood pressure (137/ $84 \mathrm{~mm} \mathrm{Hg}$ vs $108 / 64 \mathrm{~mm} \mathrm{Hg}$ ). Hypertension and older age ( $>60$ years) have an additive effect on reducing nitric oxide bioavailability and increasing oxidative stress. ${ }^{30}$ Additionally, the sensitivity of the endothelium to detect shear stress and trigger nitric oxide synthesis may be reduced. Aged endothelial cells in vitro exhibit 
impaired eNOS protein upregulation in response to shear stress compared with young cells cultured under identical conditions. ${ }^{19}$ Thus, a greater shear stress stimulus may be required to induce increases in nitric oxide in the present cohort.

\section{Circulating angiogenic cells were not mobilised following exercise}

The present study is the first to measure CAC mobilisation following exercise in postmenopausal women and use novel comparisons between interval and continuous exercise sessions. Although some studies have observed acute increases in CAC concentrations following maximal and submaximal exercise in healthy and diseased populations, ${ }^{14} \quad 31 \quad 32$ others report no change. ${ }^{33}$ We observed no increase in CACs following continuous and interval exercise at moderate and heavy intensities. These discrepancies might be explained by differing populations, definitions of CACs, exercise stimuli and the techniques used to numerate cells. However, acute exercise-induced CAC mobilisation is mechanistically driven by an increase in shear stress-induced nitric oxide. ${ }^{14}$ Thus, if endothelial sensitivity is impaired in postmenopausal women, it may well be that a larger magnitude and/or volume of shear stress are required to mobilise CACs. This could be achieved by exercising at greater work rates or by repeated acute bouts in a training programme.

\section{Interval exercise acutely increases circulating angiogenic cell functional capacity}

A low capacity of cultured CACs to form colonies is associated with a greater risk of CVD. ${ }^{4}$ The increase in CFUs following interval exercise regardless of intensity, but not following continuous exercise, suggests that interval exercise is more effective at increasing the capacity for endothelial repair by CACs among postmenopausal women. However, the mechanisms involved are unclear.

In vitro characterisation studies have demonstrated that CFUs are a heterogeneous population of aggregated monocytes and $\mathrm{T}$ cells ${ }^{35}$ and the assay reflects the intercellular communication of these cell populations. ${ }^{18}$ The ability to form CFUs depends on angiogenic $\mathrm{T}$ cells (located in the centre of the CFU colonies) that express the platelet endothelial cell adhesion molecule (CD31) and the stromal-derived factor-1 receptor (CXCR4). ${ }^{20}{ }^{36}$ Higher levels of circulating angiogenic $\mathrm{T}$ cells are associated with more CFUs in vitro, even when equal numbers of peripheral blood mononuclear cells are cultured, ${ }^{20}$ while lower levels are associated with older age and increased CVD risk. ${ }^{20}{ }^{36}$ Angiogenic $\mathrm{T}$ cells are mobilised immediately post exercise, and thus, it may be that interval exercise mobilised circulating angiogenic $\mathrm{T}$ cells to a greater extent than continuous exercise, thus, enabling more CFUs to form in vitro. Future studies should measure whether more angiogenic $\mathrm{T}$ cells $\left(\mathrm{CD} 3^{+} \mathrm{CD} 31^{+-}\right.$ $\mathrm{CXCR}^{+}$) are present post exercise.
Angiogenic $\mathrm{T}$ cells in culture may also enable CACs to form colonies through the secretion of proangiogenic cytokines. ${ }^{20}$ Messenger RNA expression of genes involved in immune and $\mathrm{T}$ cell function (eg, interleukin (IL)- $1 \beta$ and IL-8) are upregulated following acute cycling exercise. ${ }^{37}$ It is plausible that interval but not continuous exercise induced a change in this gene expression. Future studies should characterise the phenotype and gene expression of CFUs post exercise.

The mechanisms for increased CFUs post-interval exercise but not continuous exercise remain to be fully elucidated. Interval exercise induces greater peak heart rates and fluctuations in vascular shear rate profiles compared with moderate-intensity continuous exercise. $^{11} 1238$ Given that differentiation of peripheral blood mononuclear cells into different $\mathrm{T}$ cell subtypes is dependent on cytokine and catecholamine (ie, epinephrine, norepinephrine and cortisol) concentrations, ${ }^{23} 37{ }^{39}$ the repeated fluctuations to higher work rates during interval exercise may act as a greater stimulus for angiogenic $\mathrm{T}$ cell mobilisation and activation essential for CFUs in vitro. Indeed, a recent study demonstrated that highly differentiated $\mathrm{T}$ cells were increased to a greater extent following interval exercise compared with continuous exercise, and regulatory $\mathrm{T}$ cells were only mobilised following interval exercise, likely due to increased plasma epinephrine. ${ }^{22}$

\section{STRENGTHS AND LIMITATIONS}

A strength of this study is the cross-over design which reduces between-participant variability as each participant acts as their own control. We recognise that the inclusion of a non-exercise control group would have further supported the conclusion that acute interval exercise increases CFU number. However, given that $30 \mathrm{~min}$ of continuous exercise did not alter CFU number we are confident using this as our reference group. Additionally, the mean insonation angle of $68^{\circ}$ may overestimate blood velocity ${ }^{26}$; however, we reduced this impact by maintaining the same angle before and after exercise for each participant. It is important to note that this study only investigated the effects of single acute bouts of exercise on endothelial function and CAC number/function in postmenopausal women; different effects might be observed following repeated exercise sessions over longer time periods.

\section{CONCLUSIONS AND FUTURE WORK}

The UK government recommended guidelines of 30 min of moderate-intensity continuous exercise do not have an immediate impact on endothelial function and CAC number and function in postmenopausal women. In contrast, while MOD-INT or HEAVY-INT exercise did not increase the mobilisation of CACs, it did increase the colony-forming ability of peripheral blood mononuclear cells potentially involved in the repair of vascular damage. The potential impact of interval exercise for vascular health and repair in postmenopausal women 
and other populations that are at risk of developing CVD is significant. Studies manipulating the magnitudes and fluctuations in shear are now imperative.

Acknowledgements The authors thank all the study volunteers for taking part in this project. This article includes some text that is similar to that from the first author's PhD thesis(9).

Contributors KMB and MR designed the study. MR and EH performed data collection. All authors contributed to data analysis and interpretation and drafting of the manuscript.

Funding This study was funded by a British Heart Foundation Project Grant 378 (PG/08/060/25340).

\section{Competing interests None declared.}

Ethics approval University of Leeds Faculty of Biological Sciences Ethics Committee.

\section{Provenance and peer review Not commissioned; externally peer reviewed.}

Open Access This is an Open Access article distributed in accordance with the terms of the Creative Commons Attribution (CC BY 4.0) license, which permits others to distribute, remix, adapt and build upon this work, for commercial use, provided the original work is properly cited. See: http:// creativecommons.org/licenses/by/4.0/

(C) Article author(s) (or their employer(s) unless otherwise stated in the text of the article) 2017. All rights reserved. No commercial use is permitted unless otherwise expressly granted.

\section{REFERENCES}

1. Taddei S, Virdis A, Ghiadoni L, et al. Menopause is associated with endothelial dysfunction in women. Hypertension 1996;28:576-82.

2. Rakobowchuk M, Harris E, Taylor A, et al. Heavy and moderate interval exercise training alters low-flow-mediated constriction but does not increase circulating progenitor cells in healthy humans. Exp Physiol 2012;97:375-85

3. Aragona CO, Imbalzano E, Mamone F, et al. Endothelial Progenitor Cells for Diagnosis and Prognosis in Cardiovascular Disease. Stem Cells Int 2016;2016:1-12.

4. Hill JM, Zalos G, Halcox JP, et al. Circulating endothelial progenitor cells, vascular function, and cardiovascular risk. N Engl J Med 2003;348:593-600.

5. Kunz GA, Liang G, Cuculi F, et al. Circulating endothelial progenitor cells predict coronary artery disease severity. Am Heart $J$ 2006;152:190-5.

6. Iwakura A, Luedemann C, Shastry S, et al. Estrogen-mediated, endothelial nitric oxide synthase-dependent mobilization of bone marrow-derived endothelial progenitor cells contributes to reendothelialization after arterial injury. Circulation 2003;108:3115-21.

7. Mosca L, Benjamin EJ, Berra K, et al. Effectiveness-based guidelines for the prevention of cardiovascular disease in women2011 update: a guideline from the american heart association. Circulation 2011;123:1243-62.

8. Swift DL, Earnest CP, Blair SN, et al. The effect of different doses of aerobic exercise training on endothelial function in postmenopausal women with elevated blood pressure: results from the DREW study. Br J Sports Med 2012;46:753-8.

9. Attipoe S, Park JY, Fenty N, et al. Oxidative stress levels are reduced in postmenopausal women with exercise training regardless of hormone replacement therapy status. J Women Aging 2008;20(12):31-45.

10. Tjønna AE, Lee SJ, Rognmo $\varnothing$, et al. Aerobic interval training versus continuous moderate exercise as a treatment for the metabolic syndrome: a pilot study. Circulation 2008;118:346-54.

11. Wisløff U, Støylen A, Loennechen JP, et al. Superior cardiovascular effect of aerobic interval training versus moderate continuous training in heart failure patients: a randomized study. Circulation 2007; 115:3086-94.

12. Harris $E$, Rakobowchuk M, Birch KM. Sprint interval and sprint continuous training increases circulating CD34+ cells and cardiorespiratory fitness in young healthy women. PLOS One 2014;9:e108720.
13. Ekkekakis $P$. Let them roam free? Physiological and psychological evidence for the potential of self-selected exercise intensity in public health. Sports Med 2009;39:857-88.

14. Cubbon RM, Murgatroyd SR, Ferguson C, et al. Human exerciseinduced circulating progenitor cell mobilization is nitric oxidedependent and is blunted in South Asian men. Arterioscler Thromb Vasc Biol 2010;30:878-84.

15. Fadini GP, de Kreutzenberg S, Albiero M, et al. Gender differences in endothelial progenitor cells and cardiovascular risk profile: the role of female estrogens. Arterioscler Thromb Vasc Biol 2008;28:997-1004.

16. Harris E. Vascular health and repair in women across the lifespan: effect of exercise. Leeds, UK: University of Leeds, 2013.

17. Harvey PJ, Morris BL, Kubo T, et al. Hemodynamic after-effects of acute dynamic exercise in sedentary normotensive postmenopausal women. J Hypertens 2005;23:285-92.

18. Hirschi KK, Ingram DA, Yoder MC. Assessing identity, phenotype, and fate of endothelial progenitor cells. Arterioscler Thromb Vasc Biol 2008;28:1584-95

19. Hoffmann J, Haendeler J, Aicher A, et al. Aging enhances the sensitivity of endothelial cells toward apoptotic stimuli: important role of nitric oxide. Circ Res 2001;89:709-15.

20. Hur J, Yang HM, Yoon $\mathrm{CH}$, et al. Identification of a novel role of $\mathrm{T}$ cells in postnatal vasculogenesis: characterization of endothelial progenitor cell colonies. Circulation 2007;116:1671-82.

21. Jungersten L, Ambring A, Wall B, et al. Both physical fitness and acute exercise regulate nitric oxide formation in healthy humans. $J$ Appl Physiol 1997;82:760-4.

22. Krüger K, Alack K, Ringseis R, et al. Apoptosis of T-Cell Subsets after Acute High-Intensity Interval Exercise. Med Sci Sports Exerc 2016;48:2021-9.

23. Krüger $\mathrm{K}$, Lechtermann $\mathrm{A}$, Fobker $\mathrm{M}$, et al. Exercise-induced redistribution of $T$ lymphocytes is regulated by adrenergic mechanisms. Brain Behav Immun 2008;22:324-38.

24. Bowen TS, Cannon DT, Begg G, et al. A novel cardiopulmonary exercise test protocol and criterion to determine maximal oxygen uptake in chronic heart failure. J Appl Physiol 2012;113:451-8.

25. Beaver WL, Wasserman K, Whipp BJ. A new method for detecting anaerobic threshold by gas exchange. J Appl Physiol 1986;60:2020-7.

26. Thijssen DH, Black MA, Pyke KE, et al. Assessment of flowmediated dilation in humans: a methodological and physiological guideline. Am J Physiol Heart Circ Physiol 2011;300:H2-H12.

27. Bull FC and the expert working groups. Physical Activity Guidelines in the U.K: Review and Recommendations. Loughborough University: School of Sport, Exercise and Health Sciences, 2010.

28. Rossiter HB. Exercise: Kinetic considerations for gas exchange. Compr Physiol 2011;1:203-44.

29. Turner AP, Cathcart AJ, Parker ME, et al. Oxygen uptake and muscle desaturation kinetics during intermittent cycling. Med Sci Sports Exerc 2006;38:492-503.

30. Taddei S, Virdis A, Ghiadoni L, et al. Age-related reduction of NO availability and oxidative stress in humans. Hypertension 2001;38:274-9.

31. Laufs $\mathrm{U}$, Urhausen $\mathrm{A}$, Werner $\mathrm{N}$, et al. Running exercise of different duration and intensity: effect on endothelial progenitor cells in healthy subjects. Eur J Cardiovasc Prev Rehabil 2005;12:407-14.

32. Möbius-Winkler S, Hilberg T, Menzel K, et al. Time-dependent mobilization of circulating progenitor cells during strenuous exercise in healthy individuals. J App/ Physiol 2009;107:1943-50.

33. Thijssen DH, Vos JB, Verseyden C, et al. Haematopoietic stem cells and endothelial progenitor cells in healthy men: effect of aging and training. Aging Cell 2006;5:495-503.

34. Van Craenenbroeck EM, Hoymans VY, Beckers PJ, et al. Exercise training improves function of circulating angiogenic cells in patients with chronic heart failure. Basic Res Cardiol 2010;105:665-76.

35. Rohde E, Bartmann C, Schallmoser K, et al. Immune cells mimic the morphology of endothelial progenitor colonies in vitro. Stem Cells 2007:25:1746-52.

36. Wilde B, Mertens A, Arends SJ, et al. Endothelial progenitor cells are differentially impaired in ANCA-associated vasculitis compared to healthy controls. Arthritis Res Ther 2016;18:147.

37. Ulven SM, Foss SS, Skjølsvik AM, et al. An acute bout of exercise modulate the inflammatory response in peripheral blood mononuclear cells in healthy young men. Arch Physiol Biochem 2015;121:41-9.

38. Tordi N, Mourot L, Colin E, et al. Intermittent versus constant aerobic exercise: effects on arterial stiffness. Eur J Appl Physiol 2010;108:801-9.

39. Petersen AM, Pedersen BK. The anti-inflammatory effect of exercise. $J$ Appl Physiol 2005;98:1154-62. 